\title{
Estimating flood damage to railway infrastructure - the case study of the March River flood in 2006 at the Austrian Northern Railway
}

\author{
P. Kellermann ${ }^{1}$, A. Schöbel ${ }^{2}$, G. Kundela ${ }^{3}$, and A. H. Thieken ${ }^{1}$ \\ ${ }^{1}$ Institute of Earth and Environmental Science, University of Potsdam, Karl-Liebknecht-Straße 24-25, \\ 14476 Potsdam-Golm, Germany \\ ${ }^{2}$ Open Track Railway Technology GmbH, Kaasgrabengasse 19/8, 1190 Vienna, Austria \\ ${ }^{3}$ ÖBB-Infrastruktur AG, Praterstern 3, 1020 Vienna, Austria \\ Correspondence to: P. Kellermann (patkell@uni-potsdam.de)
}

Received: 30 March 2015 - Published in Nat. Hazards Earth Syst. Sci. Discuss.: 16 April 2015

Accepted: 29 October 2015 - Published: 10 November 2015

\begin{abstract}
Models for estimating flood losses to infrastructure are rare and their reliability is seldom investigated although infrastructure losses might contribute considerably to the overall flood losses. In this paper, an empirical modelling approach for estimating direct structural flood damage to railway infrastructure and associated financial losses is presented. Via a combination of event data, i.e. photodocumented damage on the Northern Railway in Lower Austria caused by the March River flood in 2006, and simulated flood characteristics, i.e. water levels, flow velocities and combinations thereof, the correlations between physical flood impact parameters and damage occurred to the railway track were investigated and subsequently rendered into a damage model. After calibrating the loss estimation using recorded repair costs of the Austrian Federal Railways, the model was applied to three synthetic scenarios with return periods of 30, 100 and 300 years of March River flooding. Finally, the model results are compared to depth-damagecurve-based approaches for the infrastructure sector obtained from the Rhine Atlas damage model and the Damage Scanner model. The results of this case study indicate a good performance of our two-stage model approach. However, due to a lack of independent event and damage data, the model could not yet be validated. Future research in natural risk should focus on the development of event and damage documentation procedures to overcome this significant hurdle in flood damage modelling.
\end{abstract}

\section{Introduction}

Railway infrastructure plays a crucial role in ensuring transportation of people and goods and, thus, contributes to economic and societal welfare. River floods, however, pose a great threat to the network's reliability and continuously cause significant direct damage (Nester et al., 2008; Moran et al., 2010a, b). In 2006, for example, a 100-year flood event occurred at the lower reach of the river March, which is located at the border of (Lower) Austria and Slovakia. During this event, the average flow rate of $108 \mathrm{~m}^{3} \mathrm{~s}^{-1}$ of the March in this section was exceeded nearly 13 times resulting in a peak flow rate of $1400 \mathrm{~m}^{3} \mathrm{~s}^{-1}$. The maximum water level lasted for nearly 2.5 days and flow velocities were rather low (Godina et al., 2007). The flood affected an important connection line of the Austrian Federal Railways (ÖBB) between Vienna and the Czech Republic, the Northern Railway, along a section of around $10 \mathrm{~km}$ causing repair costs of more than EUR 41.4 million (Moran et al., 2010a; ÖBB-Infrastruktur AG, personal communication, 2014) and a complete shutdown of passenger and freight operations for several months (Moran et al., 2010b). This event fully demonstrates the high vulnerability of railway infrastructure to floods. Hence, there is a clear need for valuable information on potential risk hot spots as well as on expected flood damage in order to support strategic decision-making in flood risk management.

Modelling flood damage to transportation infrastructure, however, is mostly neglected in natural hazards and risks research so far. Merz et al. (2010) indicated that knowledge 
of damage mechanisms as well as crucial in-depth information and data for the development of appropriate model approaches is still scarce in the infrastructure sector, whereupon existing approaches are still subject to very high uncertainties. Kunert (2010) outlined that mainly unit loss assessments can be found in literature, whereas (empirical) flood damage functions have widely been used for loss estimation in the residential sector. A popular example is the Multi-Coloured Manual (MCM), the most advanced method for flood damage estimation within Europe (e.g. PenningRowsell and Chatterton, 1977; Penning-Rowsell et al., 1992, 2005, 2010, 2013; Jongman et al., 2012). Therein, direct flood damages in the transport infrastructure sector are only roughly estimated by a percentage share of property losses on the basis of empirical data of the summer floods in the UK in 2007 (Jongman et al., 2012). However, the focus of the MCM lies on the estimation of indirect losses due to traffic disruptions (e.g. additional travel time). A few established flood damage models, e.g. the Rhine Atlas damage model (RAM) or the Damage Scanner model (DSM), actually do also consider direct damage to infrastructure by use of depth-damage curves. However, only aggregated CORINE land-use data containing a large variety of urban infrastructure and lifeline elements are used therein (Bubeck et al., 2011; Jongman et al., 2012). Due to the missing distinction of sub-classes in the CORINE Land Cover data, there is no detailed information on the share of damage to transport infrastructure in these model outputs. By reviewing the recorded losses of the Elbe flood of 2002 and the contributions of damage categories to overall losses, Bubeck et al. (2011) showed that both the RAM and the DSM significantly underestimate the share of damage corresponding to infrastructure, since the models result in a share of $1.6 \%$ (RAM) and $2.1 \%$ (DSM). However, the share of damage to infrastructure alone amounted to around $14 \%$ (national) and $17 \%$ (municipal) during the 2002 floods (Pfurtscheller and Thieken, 2013). With respect to the Elbe flood in 2002, the damage to municipal infrastructure even comprised about $20 \%$ of overall losses (Bubeck et al., 2011). Since roads and bridges incurred the greatest share in the infrastructure sector during the Elbe flood, Bubeck et al. (2011) concluded that using land-use maps as input data consisting of aggregated information on asset values as well as coarse resolution only insufficiently reflects damage to linear structures.

The case study presented in this paper aims to develop a tool for the estimation of direct flood damage and losses to railway infrastructure derived from empirical flood damage data - the so-called RAIL model (RAilway Infrastructure Loss). Using a photographic documentation of structural damage to the double-tracked Northern Railway line caused by the March River flooding of 2006, the damage information was classified into three different damage grades. Subsequently, the correlations of the (simulated) hydraulic impacts of the event and the damage grades were investigated. After identification of the most meaningful impact parameters, we performed a set of kernel density estimations to determine the decisive thresholds of impact parameter values leading to a specific structural damage class. Finally, the structural damage classes were linked to direct economic losses and, together with the parameter thresholds, rendered into a damage model. The resulting model RAIL is capable of estimating

- expected structural damage for the standard crosssection of railway track sections and

- resulting repair costs.

This two-stage approach allows a consideration of both structural damage types and direct economic losses. Particularly the first step provides new information on the occurrence of specific flood damage grades at exposed track sections. These can then be used for different risk management purposes, e.g. for the planning of (targeted) technical protection measures. The model development with the underlying data and statistics is described in detail in the following chapter. Then, the RAIL model is applied to reanalyse the losses due to the March flooding in 2006 as well as to estimate direct flood damage to the Northern Railway and respective financial losses in cases of a 30-, 100- and 300-year flood event. Finally, the model performance is compared with the depthdamage-curve-based approaches of both the RAM and the DSM and initial conclusions for flood loss estimation in the railway transportation sector are drawn.

\section{Model development}

\subsection{Classification of structural damage}

Comprehensive research in modelling flood damage in the residential sector shows the methodological expedience to distinguish between different object classes (e.g. building types) in the model framework (e.g. Kelman and Spence, 2004; Merz et al., 2004; Maiwald and Schwarz, 2008). Accordingly, considering the general importance of certain system components for rail operations, Moran et al. (2010a) differentiate between five main classes of rail infrastructure elements: standard cross-sections, bridges, station buildings, interlocking blocks and transformer substations. For each of these components, different states of structural flood damage were determined in discussions with railway operators and engineers (see Moran et al., 2010a, b). For example, a revised version of the structural damage at standard cross-sections, which will be the focus of this paper, is depicted in Fig. 1. A railway track's standard cross-section consists of the elements substructure, superstructure, catenary and signals. The left box in Fig. 1 illustrates the damage class 1, where the track's substructure is (partly) impounded, but there is no or only little notable damage. In the middle box, the damage class 2 is depicted. The substructure and superstructure of the track section are fully inundated and significant structural 

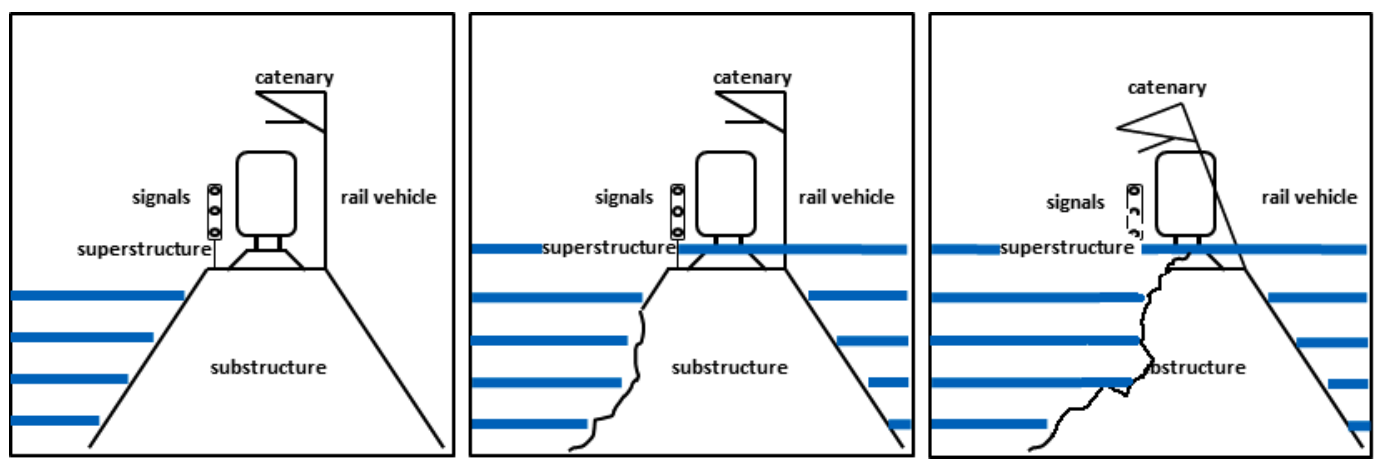

Figure 1. Damage classification scheme (adapted from Moran et al., 2010a).

damage at least to the substructure must be expected. Finally, the right box sketches the damage class 3 . Additional damage to the superstructure, catenary and/or signals must be expected here and, most commonly, the standard cross-section of the affected track section needs to be completely restored. The classes are designed for the purpose of fast and practical in-field damage assessments and scaled ordinally by progression of damage.

Using the March River flood at the Northern railway in 2006 (see introduction) as an example, the occurrence of these three damage classes was mapped based on a photographic documentation of the Austrian Federal Railways (ÖBB). These nearly 100 resulting photographs were used to evaluate and classify the structural damage at affected track sections. First, the damage patterns depicted in the photographs were georeferenced in the geoinformation system (GIS) ArcGIS 10.1 by means of distance markers along the Northern Railway track. Next, these damage data were assigned to point features, whereby each point represents a track segment with a length of $100 \mathrm{~m}$ and the highest damage pattern within each segment was decisive for the classification. In a final step, the generated damage points were each assigned to the damage class matching best, in accordance with the damage classification scheme (see Fig. 1).

\subsection{Hydraulic impact data}

The investigation of cause and effect relations between flooding and damage to railway standard cross-sections requires detailed information on the magnitudes of flood impact parameters at relevant damage spots. Similar to Kreibich et al. (2009), we investigated the relation between structural damage and five potential hydraulic impact parameters, i.e. water level, flow velocity, energy head, intensity and indicator of flow force, whereby the three latter ones are different combinations of water level and flow velocity using the following formulae:

energy head: $E=h+v^{2} / 2 g$,

intensity: $I=v \cdot h$, indicator for flow force: $\mathrm{IF}=h \cdot v^{2}$,

where $h$ is water level [m], $v$ is flow velocity $\left[\mathrm{m} \mathrm{s}^{-1}\right]$ and $g$ is acceleration of gravity $=9.81 \mathrm{~m} \mathrm{~s}^{-2}$.

Since the above-mentioned event and damage documentation from the ÖBB provide no quantitative information on such flood characteristics, a transient hydraulic simulation of the March flood in 2006 was consulted. The simulation was calibrated on the basis of the March flood waves in 1997 and 1999. During the flood in 2006, three breaches occurred at different times along the flood protection levee at the March River (see Fig. 5), which partly influenced the waveform of the event and, thus, were also considered in the simulation. However, since only scarce information on the exact size of the breaches and their development over time was available, they could only be reproduced with limited accuracy (Humer and Schwingshandl, 2009a). The model validation was carried out by using recorded discharge data at the gauges Hohenau, Angern, Baumgarten, Marchegg and Dürnkrut as well as observed peak water levels along the river channel during the flooding in 2006. The temporal evolvement of the flood wave was reproduced very well (Humer and Schwingshandl, 2009a). The peak water levels were overestimated by the model by around 8 to $12 \mathrm{~cm}$, depending on the reference gauge (Humer and Schwingshandl, 2009a).

Using the simulated water levels and flow velocities for the entire flood area on a $1 \mathrm{~m}$ grid as input data, the combined parameters (i.e. $E, I$ and IF) were computed in ArcGIS 10.1 Raster Calculator.

\subsection{Derivation of the damage model}

The development of the flood damage model is essentially based on the significance of the correlation between the hydraulic flood impact and empirical damage patterns that occurred in 2006. Within the GIS, the Northern Railway is represented as a common linear feature. In order to account for the width of a multi-track standard cross-section and its potential impact area for floods, a spatial extension, i.e. a buffer zone, needs to be attached to each segment's side facing the 
March River. Since this spatial limitation of causality is the decisive factor for the model's validity, the buffer width has to be chosen sensibly. We therefore extracted hydraulic input data by using buffer widths of $5,10,20,50$ and $100 \mathrm{~m}$ in order to test the sensitivity of this factor to the significance of the correlations. By overlapping the buffer polygons with the hydraulic raster data of the March flood of 2006, those without at least a partial exposure to the simulated inundated area were excluded and the remaining polygons were taken as the relevant impact areas in the hydraulic simulation. Next, basic descriptive statistics were calculated for the extracted parameter values, whereby the respective mean values of all pixels of the five chosen flood impact parameters that (at least partly) overlap a buffer zone were further considered in the model development. In addition, the maximum values were also checked and differences will be briefly discussed.

The idea of the proposed flood damage model RAIL is to identify statistically significant correlations between different flood impacts and structural damage classes using the data basis described in the Sects. 2.1 and 2.2. Since the dependent variable (structural damage) is given on an ordinal scale, the nonparametric Spearman's rank correlation coefficient (also: Spearman's rho) was used to perform this analysis, whereby a correlation with a coefficient equal or superior to 0.5 was considered to be meaningful. Based on these criteria, the major purpose of our approach was to initially estimate the structural damage class to be expected for a given impact at exposed track sections. Since the damage classification (see Sect. 2.1 and Fig. 1) is discrete and distinct, the use of steady curve progressions (e.g. regression models) is not suitable to describe the damage evolution. Instead, we strive to derive clear thresholds of parameter values for the assignment of an unambiguous damage class to each track segment granting sufficient validity of the model framework. Hence, we performed a set of kernel density estimations (KDE) to compute the empirical probability density distributions (Gaussian kernel) for the values of the impact parameters for each of the three damage classes. The intersections of the individual curves were subsequently used to determine the thresholds of parameter values in the RAIL model to assign the most likely structural damage class to each track segment.

In the final step of the model development, a financial loss was estimated for each structural damage class. Hereby, the following standard costs were considered: (1) costs of loss assessment/documentation, (2) cost for track cleaning per running metre (rm) and (3) standard cross-section repair costs per rm as defined by Austrian railway infrastructure experts (BMLFUW, 2008). These three cost types were individually combined for each damage class according to the corresponding damage pattern (see Fig. 1). Table 1 shows both the combined standard costs of a double-tracked segment per $\mathrm{rm}$ and the resultant costs for a $100 \mathrm{~m}$ track segment for all three damage classes.
Table 1. Standard repair costs per $100 \mathrm{~m}$ segment of a doubletracked railway standard cross-section. The costs of damage class 1 are attributable to damage documentation and cleaning of the track segment. The standard repair costs for damage class 2 were already calibrated by adding a coefficient of 0.25 (see Sect. 2.4). The cost value for damage class 3 complies with the overall damage potential of a $100 \mathrm{~m}$ track segment, including costs for damage documentation and cleaning.

\begin{tabular}{lccc}
\hline & Damage class 1 & Damage class 2 & Damage class 3 \\
\hline $\begin{array}{l}\text { Costs per } \\
100 \mathrm{~m} \\
\text { segment }\end{array}$ & EUR 11700 & EUR 135 550 & EUR 702 200 \\
\hline
\end{tabular}

\subsection{Calibration of loss estimates}

Since the substructure is the most expensive system component of a railway standard cross-section, it requires special attention regarding its notably high weighting within the estimation of repair costs. In other words, the individual damage grade of the affected substructure can significantly bias the loss estimation, particularly because the underlying table of standard costs for the calculation only contains costs of full restoration providing no further graduation of costs for minor repairs (e.g. tamping of the substructure). However, when a track segment is classified as damage class 2 , implying a substantial damage to the substructure, it is not fully assured that full restoration is definitely required. Our approach was, therefore, to calibrate the loss estimates by determining a proportional factor for damage to the substructure in damage class 2 on the basis of empirical loss data of the March River flood in 2006. By knowing the exact length of the damaged track section, the individual damage grade of the track segments as well as the total repair costs of the ÖBB, the model's boundary conditions could be set commensurate with the event. This was necessary as not all segments, which are exposed to flooding, were damaged during the March flood mainly due to effective flood protection measures. Now being applied with varying coefficients of cost calculation for the restoration of the substructure (damage class 2), the model was iteratively adjusted to the real expenses.

\subsection{Comparing the RAIL model to RAM and DSM}

Information on damage to the infrastructure sector has only been scarcely considered in flood damage modelling so far (see Sect. 1). However, initial approaches are being implemented, for example, in the RAM and the DSM. The presented damage model RAIL was compared to these two models from ICPR (2001) and Klijn et al. (2007) in order to obtain comparative values and a further performance indication.

The RAM was developed for the International Commission for the Protection of the Rhine (ICPR, 2001; Bubeck et 

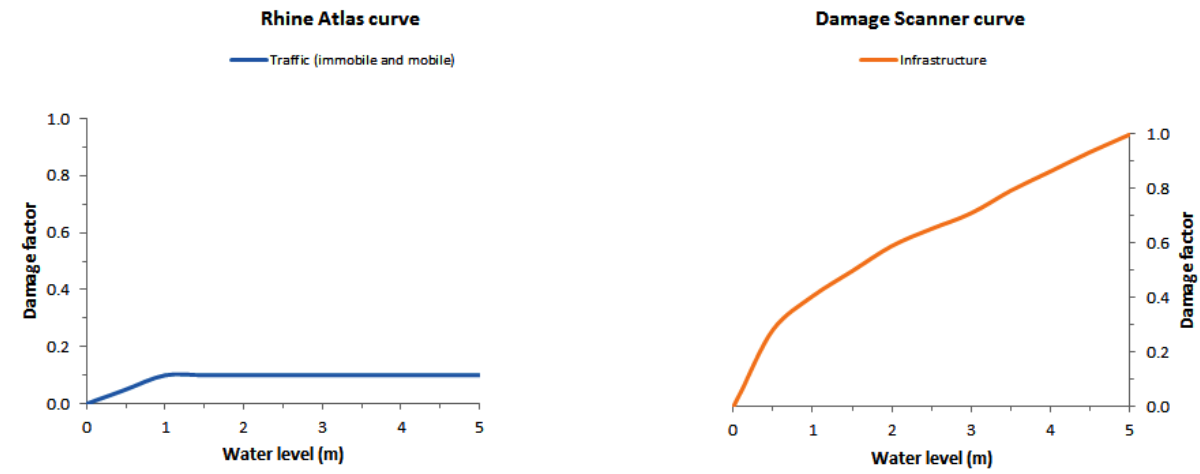

Figure 2. Damage curves used in the Rhine Atlas (left panel) and the Damage Scanner model (right panel) (adopted from Bubeck et al., 2011).

al., 2011). Derived from the empirical flood damage database HOWAS, the depth-damage functions were created to estimate direct tangible flood damage potentials for five reclassified CORINE land-use classes depending on inundation depths (ICPR, 2001; Bubeck et al., 2011). Each of the functions is linked to a certain value of maximum damage (damage potential) in order to calculate the absolute loss per grid cell. The damage potential in the RAM was derived from gross underlying asset values as at 2001 (ICPR, 2001). Additional information on the RAM can be found e.g. in ICPR (2001) or Bubeck and de Moel (2010). Figure 2 (left panel) shows the damage curve in RAM for the land-use type "traffic", which corresponds to the infrastructure sector.

The DSM is based on the standard software for estimation of flood damage in the Netherlands, the Highwater Information System - Damage and Casualties Module (HIS-SSM) (Jongman et al., 2012). It was developed to obviate the disadvantage of the HIS-SSM model to require highly detailed input data on individual asset units. Due to limited availability of data on the object scale, the DSM uses only aggregated land-use data as inputs and is designed for estimations at the regional scale (Jongman et al., 2012). Differently from the RAM, this damage model has a more synthetic origin of development as its depth-damage functions are mainly derived from expert judgement, although some empirical information was used, too (Bubeck et al., 2011). Figure 2 (right panel) illustrates the damage curve shape for the land-use class "infrastructure". Further information on the DSM is provided e.g. in Klijn et al. (2007) or Bubeck and de Moel (2010).

Both the RAM and the DSM estimate monetary losses by calculating the ratio of a predefined maximum damage depending on the particular inundation depths. In order to facilitate the comparison of RAM and DSM with the RAIL model, the two individual damage potentials for infrastructure were replaced by the ÖBB standard cross-section repair costs (see Table 1). Following the rationale that the damage potential of a railway track is a constant value, the model comparison is now based on the same price level. In a next step, the water levels from the hydraulic simulations were used as input for the infrastructure damage functions to calculate both total costs and respective difference factors to the RAIL model.

\section{Statistical review and model adjustments}

In this section, the results of the statistical review of the model setup and consequential model adjustments are presented.

The classification of structural damage on the basis of the photographic documentation (see Sect. 2.1) resulted in a sample size of 37 damage segments. After both the (dependent) variable damage class and the (independent) variables of flood impact were tested positive on normal distribution (Shapiro-Wilk test), the correlation coefficients were determined on the basis of Spearman's rho. Table 2a provides all Spearman's rho values resulting from the sensitivity analysis on buffer widths. The analysis revealed that both the strength and the direction of the correlation react very sensitively to the size of the area considered for potential flood impact. On the whole, it is notable that the correlation coefficients are strongly decreasing with increasing buffer width. However, there is a temporary increase in Spearman's rho for the buffer width of $20 \mathrm{~m}$ for the parameters $v, I$ and IF. From a width of $50 \mathrm{~m}$ the coefficients even begin to turn negative, which runs counter to the physical rationale of damage development. Solely the coefficients concerning the parameters $h$ and $E$ meet the defined threshold for at least some buffer widths, whereas the parameters $v, I$ and IF are considerably below the threshold level of significance throughout all widths. The $5 \mathrm{~m}$ buffer obtained slightly higher coefficients than the $10 \mathrm{~m}$ variant. However, since the inner boundary of the buffers are set to the centre of the track lane, the buffer width of $5 \mathrm{~m}$ would be insufficient to cover the entire rail embankment and, thus, to enclose all elements of the cross-section adequately. Due to this technical consideration, the buffer width of $5 \mathrm{~m}$ was neglected in retrospect as considered to be too 

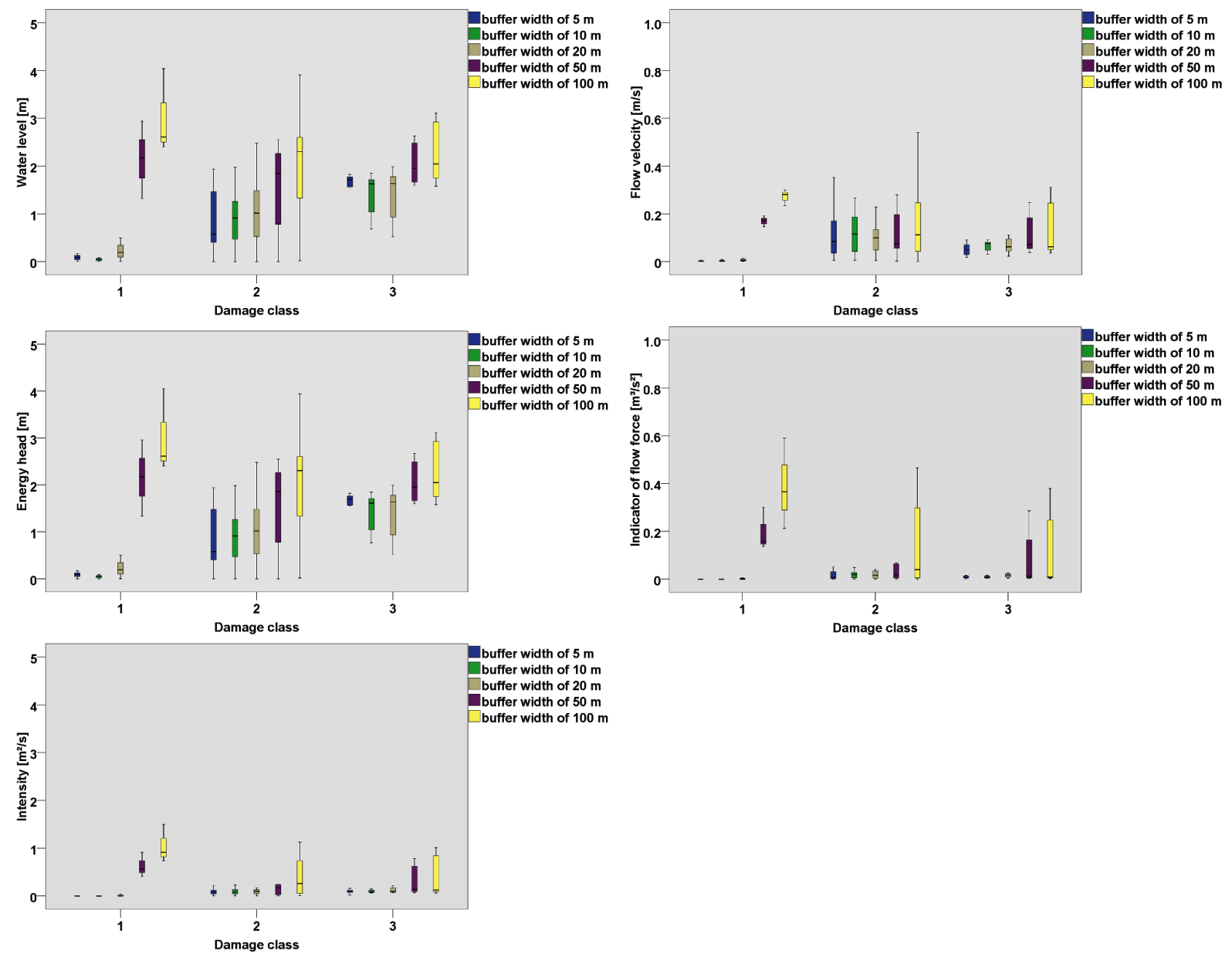

Figure 3. Box plots displaying the summary statistics of each impact parameter per damage class and for varying buffer widths.

narrow to represent the double-track standard cross-section of the Northern Railway adequately.

The summary statistics of the mean parameter values per damage class are illustrated by the box plots in Fig. 3 . Therein, only the median of $h$ and $E$ increases with increasing damage classes and, thus, is corresponding to the general logic of damage evolution. All other parameters are contradictory to it since the median values partly decrease with increasing damage. Furthermore, the box plots clearly indicate a varying scatter range of the data as well as different natures of distribution for different buffer widths of the same parameter since both the lengths of the box plots and the position of the medians within the interquartile range diversify significantly. Considering these criteria, the $10 \mathrm{~m}$ buffer width features lower data scattering and lesser distributional skewness than widths of $20 \mathrm{~m}$ and higher. In damage classes 1 and 2 the samples of 5,10 and $20 \mathrm{~m}$ width are nearly normally distributed, whereas the widths of 50 and $100 \mathrm{~m}$ already show a distributional skewness in the data. In damage class 3, however, all box plots indicate a skewed distribution of parameter values to a greater or lesser extent. Based on the shown characteristics, the buffer width of $10 \mathrm{~m}$ was selected for investigation of the parameters $h$ and $E$, and the parameters $v$, $I$ and IF are excluded from the further investigations.

As already described in Sect. 2, the identification of relevant flood impacts is based on transient hydraulic data, whereby the mean parameter values within the buffers were used for the model development. This method was chosen with the objective to reduce possible effects of very smallscale extremes in the high-resolution input data caused, for example, by cavities. However, maximum impacts might be more relevant for the extent of damage than mean values. Yet, in order to legitimise the use of mean values, the maximum values were also investigated. Table $2 \mathrm{~b}$ provides the resulting correlation coefficients. In relative terms, the situation is similar to the findings on the basis of mean impacts, since $h$ and $E$ still show the highest correlation coefficients of all parameters and small buffer widths lead to better results than large buffer widths. In absolute terms, however, none of the combinations are meeting the defined threshold of significance of correlation and, thus, the maximum parameter values were not considered in the further course of this work. 


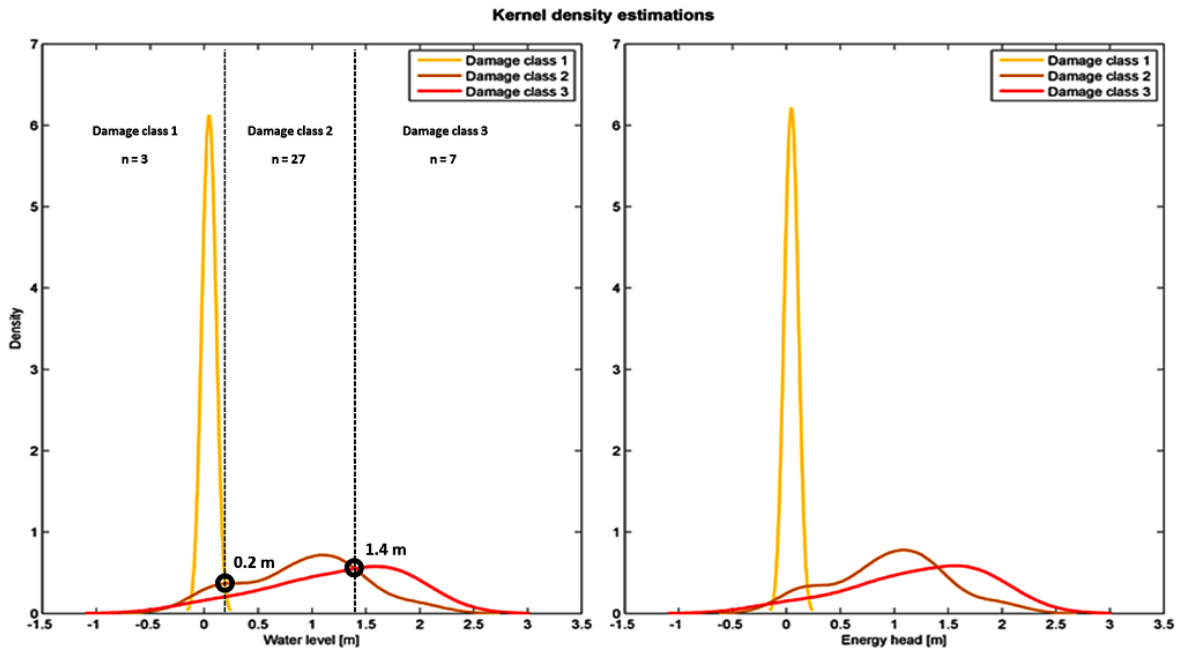

Figure 4. Kernel density plots for the impact parameters $h$ and $E$. The parameter values at the marked graph intersection points determine the thresholds in the damage model to assign the most likely damage class to each track section. The derived values apply equally to both parameters.

After identifying the impacts of concern and verifying the reference area, a KDE was performed for each parameter and damage class to derive probability-based thresholds of parameter values for the damage model. The resulting probability density plots are shown in Fig. 4. The black marks in the plot highlight the curve intersections being decisive for the threshold determination. It is apparent that there is almost no disparity perceptible between the curve shapes of the probability densities. As $E$ has an additive interrelation to $v$ - being very low for the March River flood in 2006 its values only differ marginally from the inundation depths, which explains the close similarities of the graphs. Assessing the curve progressions also points to some characteristics in the data basis. First, differing shapes of the probability density curves are apparent showing a narrow shape for damage class 1 along with a broader span for the damage classes 2 and 3. Secondly, the curve amplitudes vary greatly between damage class 1 and damage classes 2 and 3 . This can be explained by (1) the very uneven sample sizes of the individual damage classes resulting from the classification of the photographically documented damage information according to the formulated scheme (see Fig. 1) and (2) the overall coefficient of variation (0.66) of the hydraulic data within the reference areas, which is relatively high.

Overall, a few questions still remain unanswered and some key assumptions concerning the model basis could not be validated so far. First, it was taken as granted that the correlations being investigated imply causality, although the possibility remains that unidentified parameters, certain preconditions of the test track structure or other unknowns could have been either the main cause of the damage occurrence or, at least, of partial influence. Indications thereof include the rather low correlation coefficients as the chosen impact parameters just reach the defined threshold of significance as well as the fact that data scattering is noticeably increasing and distributional skewness is arising in damage class 3 . Second, there are other considerable impact parameters, such as significant flow velocities or duration of the flood impact. However, during the March River flood in 2006 only very low flow velocities occurred within the track's impact area with the result that no meaningful correlations could be found (see Table 2a). This parameter was therefore discarded in the model development. Both examples would presumably have at least some influence on damage patterns. Third, the data basis for loss estimation may contain considerable uncertainties. While the calculation of monetary losses is based on a table of standard costs for damage to individual infrastructure elements (see Sect. 2.3 and Table 1), its calibration was conducted using a single amount of total loss without detailed information on e.g. the composition of this amount, possible discounts or other price concessions. Finally, another source of uncertainty can be the missing information on the vertical extent of the track in GIS. The particular height of the track in relation to the surrounding area might change over course due to e.g. the substructure being section-wise located below surface or, reciprocally, on existing railroad embankments. In such a case, the identified local water levels are significantly biased as their reference height is the ground level.

\section{Application and evaluation}

\subsection{The March flood of 2006}

The developed flood damage model RAIL was initially run with the hydraulic input of the March River flood of 2006 in order to evaluate its performance in loss estimation. For this, 
Table 2. Spearman's rank correlation coefficients between the dependent variable "damage class" and each independent variable "impact parameter" based on the mean values (a) and maximum values (b) for varying buffer widths. The coefficients meeting the threshold level of meaningfulness, which has been set to 0.5 within this study, are highlighted in bold type. Additionally, the corresponding $p$ values (two-tailed, $5 \%$ error) are provided in brackets and in italics.

\begin{tabular}{|c|c|c|c|c|c|}
\hline $\begin{array}{l}\text { Buffer } \\
\text { width }\end{array}$ & $5 \mathrm{~m}$ & $10 \mathrm{~m}$ & $20 \mathrm{~m}$ & $50 \mathrm{~m}$ & $100 \mathrm{~m}$ \\
\hline \multicolumn{6}{|c|}{ (a) Damage class $(n=37)$} \\
\hline$h$ & $\begin{array}{c}\mathbf{0 . 5 3 2} \\
(0.001)\end{array}$ & $\begin{array}{c}\mathbf{0 . 5} \\
(0.002)\end{array}$ & $\begin{array}{r}0.381 \\
(0.020)\end{array}$ & $\begin{array}{r}0.096 \\
(0.572)\end{array}$ & $\begin{array}{l}-0.066 \\
(0.696)\end{array}$ \\
\hline$v$ & $\begin{array}{c}0.104 \\
(0.539)\end{array}$ & $\begin{array}{c}0.095 \\
(0.578)\end{array}$ & $\begin{array}{r}0.169 \\
(0.318)\end{array}$ & $\begin{array}{l}-0.106 \\
(0.531)\end{array}$ & $\begin{array}{l}-0.159 \\
(0.347)\end{array}$ \\
\hline$I$ & $\begin{array}{c}0.334 \\
(0.043)\end{array}$ & $\begin{array}{c}0.323 \\
(0.051)\end{array}$ & $\begin{array}{r}0.399 \\
(0.014)\end{array}$ & $\begin{array}{r}-0.098 \\
(0.562)\end{array}$ & $\begin{array}{l}-0.172 \\
(0.308)\end{array}$ \\
\hline IF & $\begin{array}{c}0.261 \\
(0.119)\end{array}$ & $\begin{array}{c}0.090 \\
(0.597)\end{array}$ & $\begin{array}{r}0.216 \\
(0.199)\end{array}$ & $\begin{array}{l}-0.152 \\
(0.371)\end{array}$ & $\begin{array}{l}-0.239 \\
(0.154)\end{array}$ \\
\hline$E$ & $\begin{array}{c}\mathbf{0 . 5 3 2} \\
(0.001)\end{array}$ & $\begin{array}{c}\mathbf{0 . 5 0 5} \\
(0.002)\end{array}$ & $\begin{array}{r}0.381 \\
(0.020)\end{array}$ & $\begin{array}{r}0.091 \\
(0.590)\end{array}$ & $\begin{array}{l}-0.066 \\
(0.696)\end{array}$ \\
\hline \multicolumn{6}{|c|}{ (b) Damage class $(n=37)$} \\
\hline$h$ & $\begin{array}{c}0.398 \\
(0.015)\end{array}$ & $\begin{array}{c}0.319 \\
(0.055)\end{array}$ & $\begin{array}{r}0.079 \\
(0.641)\end{array}$ & $\begin{array}{l}-0.238 \\
(0.157)\end{array}$ & $\begin{array}{l}-0.136 \\
(0.423)\end{array}$ \\
\hline$v$ & $\begin{array}{c}0.188 \\
(0.266)\end{array}$ & $\begin{array}{c}0.110 \\
(0.517)\end{array}$ & $\begin{array}{r}0.064 \\
(0.705)\end{array}$ & $\begin{array}{l}-0.332 \\
(0.045)\end{array}$ & $\begin{array}{l}-0.315 \\
(0.058)\end{array}$ \\
\hline$I$ & $\begin{array}{c}0.300 \\
(0.071)\end{array}$ & $\begin{array}{c}0.170 \\
(0.314)\end{array}$ & $\begin{array}{l}-0.020 \\
(0.909)\end{array}$ & $\begin{array}{r}-0.302 \\
(0.069)\end{array}$ & $\begin{array}{l}-0.299 \\
(0.072)\end{array}$ \\
\hline IF & $\begin{array}{c}0.251 \\
(0.134)\end{array}$ & $\begin{array}{c}0.147 \\
(0.385)\end{array}$ & $\begin{array}{l}-0.111 \\
(0.511)\end{array}$ & $\begin{array}{l}-0.300 \\
(0.071)\end{array}$ & $\begin{array}{l}-0.308 \\
(0.063)\end{array}$ \\
\hline$E$ & $\begin{array}{c}0.393 \\
(0.016)\end{array}$ & $\begin{array}{c}0.313 \\
(0.059)\end{array}$ & $\begin{array}{r}0.079 \\
(0.641)\end{array}$ & $\begin{array}{l}-0.232 \\
(0.166)\end{array}$ & $\begin{array}{l}-0.136 \\
(0.423)\end{array}$ \\
\hline
\end{tabular}

we compared the estimated total loss with recorded repair costs of the ÖBB incurred by this event. The results showed that the model overestimates the real loss by a factor of approximately 1.6 , which indicated the need for further adjustments. Therefore, we calibrated the model by means of iteratively fitting its loss estimation in damage class 2 to the real expenses (see Sect. 2.4). The calibration resulted in a cost reduction of $75 \%$ in this damage class. The overestimation bias of the RAIL model could thereby be reduced from the initial $60 \%$ to approximately $2 \%$. The result of the (calibrated) loss estimation is provided in Table 3a. Additionally, the model results for the March flood data are cartographically mapped in Fig. 5 showing the inundation areas including water levels as well as classified damage at flood-affected track segments.

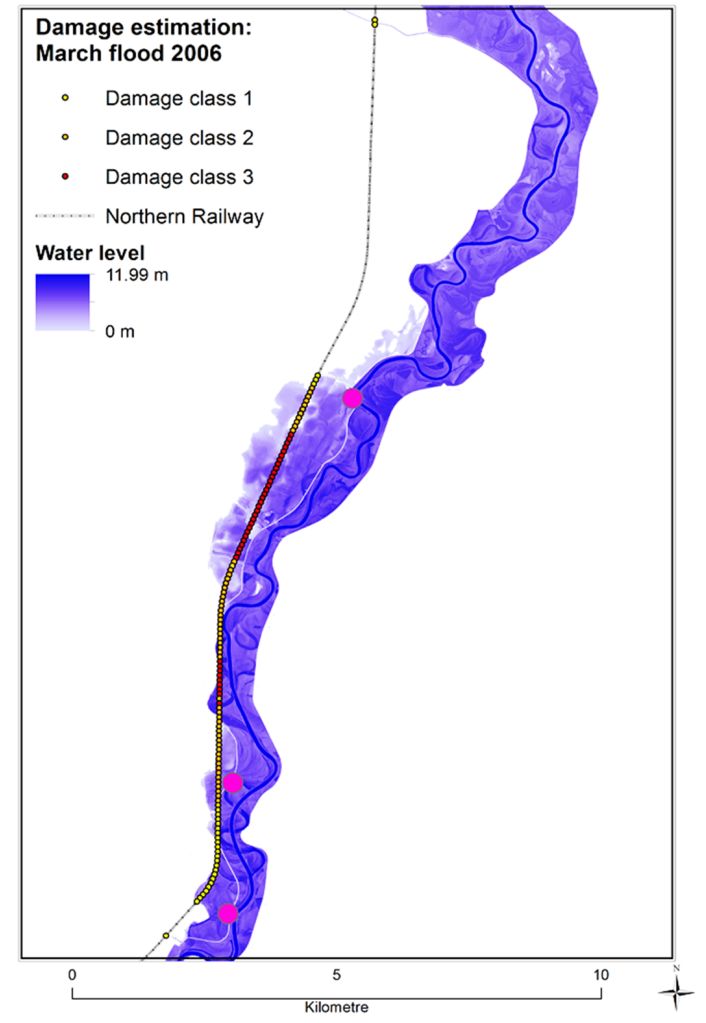

Figure 5. Estimation of damage potentials at the Northern Railway for the hydraulic conditions of the March River flood in 2006. During the event, three levee breaches occurred at three different locations along flood protection levee at the March River (see pink dots).

Although this event is classified as a 100 -year event according to the observed discharge at the gauge Angern, the inundation area in the northern half of the river section considerably differs compared to the synthetic 100 -year event (see Fig. 6 and Sect. 4.2). While the respective area was not flooded in 2006, the synthetic scenario discloses widescale inundation in this section. This is due to the difference in the underlying assumptions of levee breaches in the simulations. The hydraulic remodelling of the real flooding in 2006 considers the three actual levee breaches that have occurred during the event (see Fig. 5), whereas the synthetic 100 -year event simulation neglects these breaches but includes a levee breach scenario at the March tributary Zaya (Humer and Schwingshandl, 2009b). This naturally results in significant differences in the inundation areas as well as the hydraulic impact. Hence, there is greater exposure of the Northern Railway to the real event in 2006 and the respective total losses are more than 1.6 times higher than for the synthetic 100-year event (see Table 3a and b). The results clearly indicate the strong sensitivity of the flood damage model on the hydraulic input and its underlying assumptions.

Furthermore, it should be noted that the March flood affected only slightly more than $10 \mathrm{~km}$ of the Northern Rail- 
Table 3. Estimated frequencies of damage classes and resulting repair costs for (a) the March flood in 2006 and (b) for different hydraulic scenarios.

\begin{tabular}{|c|c|c|c|c|c|}
\hline & & Damage class 1 & Damage class 2 & Damage class 3 & $\sum$ \\
\hline \multicolumn{6}{|c|}{ (a) } \\
\hline \multicolumn{2}{|c|}{$n$} & 30 & 54 & 39 & 123 \\
\hline \multicolumn{2}{|c|}{ Repair costs } & EUR 351000 & EUR 7319700 & EUR 27385800 & EUR 35056500 \\
\hline \multicolumn{6}{|c|}{ (b) } \\
\hline \multirow{2}{*}{ HQ30 } & $n$ & 10 & 52 & 15 & 77 \\
\hline & Repair costs & EUR 117000 & EUR 7048600 & EUR 10533000 & EUR 17698600 \\
\hline \multirow{2}{*}{ HQ100 } & $n$ & 21 & 74 & 16 & 111 \\
\hline & Repair costs & EUR 245700 & EUR 10030700 & EUR 11235200 & EUR 21511600 \\
\hline \multirow{2}{*}{ HQ300 } & $n$ & 9 & 96 & 114 & 219 \\
\hline & Repair costs & EUR 105300 & EUR 13012800 & EUR 80050800 & EUR 93168900 \\
\hline
\end{tabular}

way track, whereas the flood damage model states $12.3 \mathrm{~km}$ of exposure based on the hydraulic input. This discrepancy can have numerous reasons such as insufficiently detailed information on local flood characteristics or mobile/temporal flood protection measures not being considered in the setup of the hydraulic simulation. Regarding the latter point, massive efforts were made during the event by the local fire brigade, the Austrian Armed Forces, emergency services and the police (Bezirksfeuerwehrkommando Gänserndorf, 2006). In the aftermath of the March flood event, existing technical flood protection measures have been refurbished, extended and upgraded with state-of-the-art technology in order to achieve an appropriate level of protection (HQ100) for flood-prone areas at the March River.

\subsection{Flood scenarios}

In a subsequent step, the damage model was applied to a set of hydraulic scenarios complying with synthetic 30-, 100and 300-year March River floods. The selected return periods play a major role in various natural hazard management strategies in Austria. For instance, the same return periods serve as a basis in the preparation of hazard zone maps by the Austrian Avalanche and Torrent Control (WLV). Figure 6 depicts the model results for the different synthetic scenarios sorted in ascending order according to maximum water levels. The maps show the individual inundation areas including water levels as well as the classified damage at floodaffected track segments. Primarily induced by an increasing size of the inundation area as well as higher water levels, the Northern Railway is increasingly exposed with decreasing probability of flooding. As a consequence thereof, the number of affected track segments as well as the related damage potential is rising. The model results for the estimation of monetary losses are shown in Table 3b. Basically, the calculated costs amount to a plausible order and scale as the total costs increase for lower probability events. Although the uncertainties of estimations are not being quantified, the information on the order of loss magnitudes alone is already valuable for risk management.

Within the scope of risk assessments, the expected annual damage (EAD) is also a common risk metric. The EAD is defined as the annual monetary loss that is to be statistically expected on the basis of selected hazard scenarios. Considering the available scenario bandwidth (HQ30-HQ300) in this case study, the EAD amounts to EUR 839721 . Herein, the share of loss equals to $46 \%$ for the low-probability events (HQ100-300) and 54\% for the high-/medium-probability events (HQ30-HQ100).

\subsection{Results of the model comparison}

In the final part of the study, the RAIL model was compared with the depth-damage-curve-based approaches of both the RAM and the DSM. Table 4a (March flood) and b (synthetic scenarios) show the results of loss estimation with RAM and DSM as well as the corresponding difference factors to the results of the RAIL model. As already mentioned in the introduction paragraph, the RAM and the DSM tend to underestimate damage to infrastructure for various reasons. The difference factors to the RAIL model fortify this finding, at least for railway infrastructure: the RAM estimations amount to only around a fourth of the losses compared to the results of the RAIL model. Although the DSM results are significantly better in line with our calculations, there is still a notable underestimation of around 10 to $30 \%$ of total losses except for the HQ100 scenario, where the costs are overestimated by around $10 \%$. Moreover, the absolute difference becomes stronger with rising event return period. Both comparative models seem to have no particular bias to high (or low) water levels, since there is no consistent increase (or decrease) in the difference factor with changing event probability and, associated therewith, alternating water level magnitudes. 


\section{Damage estimations}
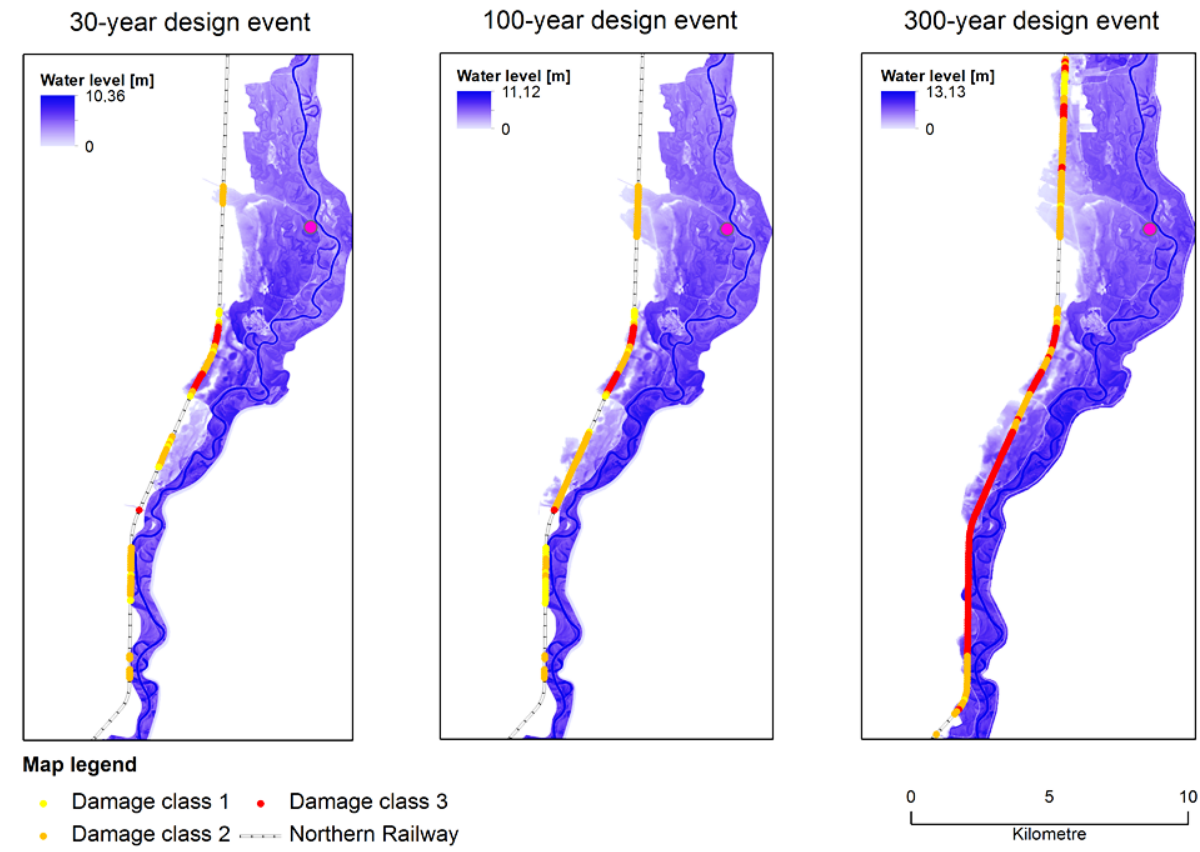

Figure 6. Estimation of damage potentials at the Northern Railway for three flood scenarios. The left map shows the model results for the hydraulic input of a synthetic 30-year event. The results for a synthetic 100-year event are illustrated in the middle map. The right map covers the results of the model application with the hydraulic input of a 300-year design event. In contrast to the hydraulic input of the March flood in 2006, the three levee breaches were not considered in these design events. Instead, a levee breach scenario at the March tributary Zaya was included (see pink dot). Hence, although the March River flood in 2006 was classified as a 100-year event, significant differences to the synthetic 100-year event can be identified (e.g. inundation area, local water levels).

Table 4. (a) Calculated monetary losses for the March flood in 2006 according to the Rhine-Atlas Model (RAM) and the Damage Scanner Model (DSM). (b) Calculated monetary losses for the synthetic flood scenarios according to RAM and DSM.

\begin{tabular}{llccc}
\hline RAM & $\begin{array}{c}\text { Difference } \\
\text { factor } \\
\text { to RAIL }\end{array}$ & DSM & $\begin{array}{c}\text { Difference } \\
\text { factor } \\
\text { to RAIL }\end{array}$ \\
\hline \multicolumn{5}{c}{ (a) } \\
\hline EUR 8 099812 & 4.3 & EUR 29 162 547 & 1.2 \\
\hline \multicolumn{5}{c}{ (b) } \\
\hline HQ30 & EUR 3 809787 & 4.6 & EUR 15 219 675 & 1.2 \\
HQ100 & EUR 5 643 006 & 3.8 & EUR 23 178 842 & 0.9 \\
HQ300 & EUR 22 688 580 & 4.1 & EUR 73 126300 & 1.3 \\
\hline
\end{tabular}

Indeed, the evaluation of the RAM and DSM via the difference factor is relativised by the fact that our developed approach of damage modelling to infrastructure could not have been validated yet due to lack of data. Nevertheless, the comparison of the RAM and DSM results for flooding in 2006 with the official repair costs of the ÖBB proves that the estimations are significantly biased, especially when considering that these reference costs refer only to the restoration of the railway standard cross-section (approx. EUR 34.3 million) and do not include the repair costs of other railway infrastructure elements, which would imply additional costs of approximately EUR 7 million (Moran et al., 2010a; ÖBBInfrastruktur AG, personal communication, 2014). Hence, the findings of this comparison indicate the relevance of the level of detail in the input data that are used for the derivation of damage functions as well as the variety of exposed assets to be considered in the damage model. Since both the RAM and the DSM use aggregated land-use data as input values, they are based on a certain degree of generalisation. Thus, the damage to railway infrastructure only marginally contributes to total damage as it is only one out of many damage categories with varying asset values and spatial configurations. Nevertheless, despite their similar modelling approach, the DSM obtains far better loss estimates in our case study. This can be explained by the fact that the DSM damage function better reflects the real damage evolution with respect to railway infrastructure. In contrast, the RAM curve does not sufficiently differentiate between certain assets of infrastructure. Instead, the approach is based on a rough average of direct tangible losses over the entire land-use class including comparatively low assets, which adversely affects the loss estimations solely for expensive infrastructure elements such as railway system components. 


\section{Conclusions}

The purpose of the approach presented in this paper was to initially estimate the expected structural damage for a given flood impact at exposed track sections. This step frequently is skipped in existing flood damage models as only (relative or absolute) monetary losses are computed. However, the localisation of significant structural damage potentials at specific track section and, coupled therewith, the identification of risk hot spots creates great added value for railway constructors and operators in terms of network and risk management. Such information allows, for example, the targeted planning and implementation of (technical) risk reduction measures. In this regard, the model performance already proves expedient as the mapped results plausibly illustrate the high damage potential of the track section located closely adjacent to the course of the river March (see Figs. 5 and 6) as well as a general accordance with inundation depths.

Basically, the RAIL model can be applied not only to estimate flood damage and related costs for specific railway lines but also to an entire railway network, providing the following two conditions are met: first, the general construction characteristics of the infrastructure must be similar to the ones of the Austrian Northern Railway. Accordingly, slab tracks (i.e. high-speed railway lines), for example, are not suitable to be investigated by RAIL since their construction design is significantly different from the design of the Northern Railway line and, hence, the derived correlations of flood impact and resulting damage are no longer valid. Second, since the RAIL model was derived from flood impacts caused by rather low flow velocities, i.e. static river flooding, and has not yet been tested for other flood types such as flash floods, it is assumed that the RAIL mode is in a first instance valid for lowland rivers. This aspect needs to be considered for an application to a broader railway network being at risk of flooding, particularly in countries with complex topography. In Austria, for example, around $65 \%$ of the national territory is located in Alpine areas mainly characterized by high relief energy and steep slopes. In such topography, fluvial natural events often show hydraulic characteristics being significantly different to static river flooding, e.g. regarding the flow velocity. Further cases and data are needed to adapt the RAIL model to such conditions.

The RAIL model could not yet be validated by an independent data set. Respective reviews are thus required when appropriate empirical data are available, and further research on potential sources of uncertainty is needed (see Sect. 3). On the latter point we intend to put special emphasis on the flow velocity $v$ as this parameter is considered to also have substantial impact on railway infrastructure above a certain magnitude. Its investigation was not suitable so far due to the fact that the March flood in 2006 - being classified as a static river flood - was characterised by very low flow velocities. Therefore, testing the model's performance in estimat- ing structural damage caused by a dynamic flood event with high flow velocities is strived for.

Further reviewing the model's loss estimation is another issue of concern. Although the approach was calibrated to real expenses due to flooding in 2006, a verification of the loss estimation accuracy against independent loss events is still missing due to data scarcity. Nevertheless, its comparison to the RAM and DSM loss estimations for the available scenarios points out that our presented approach is well under way. The most obvious difference between the RAIL model and the established tools lies in the model characteristics itself. While our approach is developed and specified only for railway infrastructure, the other two models focus on flexibility in application in a generalized manner, which of course affects their model accuracy for selective applications.

Overall, the findings of this study show that the development of reliable flood damage models is heavily constrained by the continuing lack of detailed event and damage data. Future research in natural risk should focus on the development of event and damage documentation procedures to overcome this significant hurdle in flood damage modelling.

Acknowledgements. The authors gratefully acknowledge the Austrian Federal Railways ÖBB for their substantial data supply and Raimund Heidrich from the engineering office riocom for his collaboration, data supply and advice concerning the hydraulic simulations of the March River. The research leading to these results has received funding from the EU Seventh Framework Programme, through the project ENHANCE (Enhancing risk management partnerships for catastrophic natural hazards in Europe) under grant agreement no. 308438.

Edited by: L. Ferraris

Reviewed by: J. Mysiak and another anonymous referee

\section{References}

Bezirksfeuerwehrkommando Gänserndorf: Katastropheneinsatz - Marchhochwasser 2006, Einsatzdetailbericht, Gänserndorf, 2006.

BMLFUW: Kosten-Nutzen-Untersuchungen im Schutzwasserbau Richtlinie KNU gemäß § 3 Abs. 2 Ziffer 2 WBFG, Fassung Jänner 2008, p. 28, 2008.

Bubeck, P. and de Moel, H.: Sensitivity analysis of flood damage calculations for the river Rhine, Final report, Institute for Environmental Studies, IVM, Amsterdam, 2010.

Bubeck, P., de Moel, H., Bouwer, L. M., and Aerts, J. C. J. H.: How reliable are projections of future flood damage?, Nat. Hazards Earth Syst. Sci., 11, 3293-3306, doi:10.5194/nhess-11-32932011, 2011.

Godina, R., Lalk, P., Müller, G., and Weilguni, V.: Das Hochwasser an der March im Frühjahr 2006, Beschreibung der hydrologischen Situation, Mitteilungsblatt des Hydrographischen Dienstes in Österreich, Wien, 2007.

Humer, G. and Schwingshandl, A.: Hydrodynamisches numerisches 2d-Modell der March und Thaya in Österreich, der 
Slowakei und Tschechien, AP02 - Modellkalibrierung und Verifikation, Technischer Bericht, Arge riocom, IB Humer, Aquasoli. Wien, Wien, 2009a.

Humer, G. and Schwingshandl, A.: Hydrodynamisches numerisches 2d-Modell der March und Thaya in Österreich, der Slowakei und Tschechien, AP05 - Analyse des Hochwasserwellenablaufs. Technischer Bericht, Arge riocom, IB Humer, Aquasoli. Wien, Wien, 2009b.

ICPR: Übersichtskarten der Überschwemmungsgefährdung und der möglichen Vermögensschäden am Rhein, Abschlussbericht: Vorgehensweise zur Ermittlung der möglichen Vermögensschäden, Internationale Kommission zum Schutz des Rheins, Wiesbaden, Heidelberg, Nijmegen, München, 2001.

Jongman, B., Kreibich, H., Apel, H., Barredo, J. I., Bates, P. D., Feyen, L., Gericke, A., Neal, J., Aerts, J. C. J. H., and Ward, P. J.: Comparative flood damage model assessment: towards a European approach, Nat. Hazards Earth Syst. Sci., 12, 3733-3752, doi:10.5194/nhess-12-3733-2012, 2012.

Kelman, I. and Spence. R.: An overview of flood actions on buildings. Eng. Geol., 73, 297-309, 2004.

Klijn, F., Baan, P. J. A., De Bruijn, K. M., and Kwadijk, J.: Overstromingsrisico's in Nederland in een veranderend klimaat, WL delft hydraulics, Delft, the Netherlands, Q4290, 2007.

Kreibich, H., Piroth, K., Seifert, I., Maiwald, H., Kunert, U., Schwarz, J., Merz, B., and Thieken, A. H.: Is flow velocity a significant parameter in flood damage modelling?, Nat. Hazards Earth Syst. Sci., 9, 1679-1692, doi:10.5194/nhess-9-1679-2009, 2009.

Kunert, U.: Abschätzung von Schäden im Verkehrssektor, in: Hochwasserschäden - Erfassung, Abschätzung und Vermeidung, edited by: Thieken, A. H., Seifert, I., and Merz, B., OekomVerlag, Munich, 235-252, 2010.

Maiwald, H. and Schwarz, J.: Damage and loss prediction model based on the vulnerability of building types, 4th International Symposium on Flood Defence, Toronto, Canada, 6-8 May 2008.

Merz, B., Kreibich, H., Thieken, A., and Schmidtke, R.: Estimation uncertainty of direct monetary flood damage to buildings, Nat. Hazards Earth Syst. Sci., 4, 153-163, doi:10.5194/nhess-4-1532004, 2004.

Merz, B., Kreibich, H., Schwarze, R., and Thieken, A.: Assessment of economic flood damage, Nat. Hazards Earth Syst. Sci., 10, 1697-1724, doi:10.5194/nhess-10-1697-2010, 2010.
Moran, A. P., Schöbel, A., and Thieken, A. H.: Analyse des Hochwasserrisikos von Eisenbahninfrastrukturen, alpS project 1.19ABC - Final Report, Innsbruck, unpublished, 2010a.

Moran, A. P., Thieken, A. H., Schöbel, A., and Rachoy, C.: Documentation of Flood Damage on Railway Infrastructure, in: Data and Mobility, edited by: Düh, J., Hufnagl, H., Juritsch, E., Pfliegl, R., Schimany, H.-K., and Schönegger, H., AISC 81, Heidelberg, 61-70, 2010b.

Nester, T., Schöbel, A., Drabek, U., Kirnbauer, R., and Rachoy, C.: Flood Warning System for the Austrian Railways, in: 1st Lakeside Conference on Safety in Mobility, Intelligent Weather Information Systems and Services in Traffic and Transport, Velden, Austria, 2008.

ÖBB-Infrastruktur AG: personal communication, Status as of February 2014.

Pennning-Rowsell, E. C. and Chatterton, J. B.: The benefits of flood allevation: A manual of assessment techniques, Saxon House, Farnborough, 1977.

Pennning-Rowsell, E. C., Green, C. H., Thompson, P. M., Coker, A. M., Tunstall, S. M., Richards, C., and Parker, D. J.: The economics of coastal management: a manual of benefit assessment techniques, DEFRA, London, 1992.

Penning-Rowsell, E. C., Johnson, C., Tunstall, S., Tapsell, S., Morris, J., Chatterton, J., and Green, C.: The benefits of flood and coastal risk management: a handbook of assessment techniques, Flood Hazard Research Centre, Middlesex University Press, Middlesex, 2005.

Penning-Rowsell, E., Viavattene, C., Pardoe, J., Chatterton, J., Parker, D., and Morris, J.: The Benefits of Flood and Coastal Risk Management: A Handbook of Assessment Techniques, Flood Hazard Research Centre, Middlesex, 2010.

Penning-Rowsell, E., Priest, S., Parker, D., Morris, J., Tunstall, S., Viavattene, C., Chatterton, J., and Owen, D.: Flood and Coastal Erosion Risk Management, A Manual for Economic Appraisal, Routledge/Taylor \& Francis, Abingdon, p. 420, 2013.

Pfurtscheller, C. and Thieken, A. H.: The price of safety: costs for mitigating and coping with Alpine hazards, Nat. Hazards Earth Syst. Sci., 13, 2619-2637, doi:10.5194/nhess-13-26192013, 2013. 